\title{
Productivity Analysis Method of Abnormal High-Pressure Gas Reservoir in Ying-Qiong Basin
}

\author{
Qi Zhu, Hao Liang \\ CNOOC China Ltd. Zhanjiang Branch Company, Zhanjiang, China \\ Email:2891010029@qq.com
}

How to cite this paper: Zhu, Q. and Liang, H. (2017) Productivity Analysis Method of Abnormal High-Pressure Gas Reservoir in Ying-Qiong Basin. Natural Resources, 8, 410-415.

https://doi.org/10.4236/nr.2017.86026

Received: May 18, 2017

Accepted: June 10, 2017

Published: June 13, 2017

Copyright $\odot 2017$ by authors and Scientific Research Publishing Inc. This work is licensed under the Creative Commons Attribution International License (CC BY 4.0).

http://creativecommons.org/licenses/by/4.0/

\begin{abstract}
Ying-Qiong Basin in the west of South China Sea contains plenty of abnormal high-pressure gas reservoirs, whose stress sensitivity is crucial for well productivity. To explore the influence of stress sensitivity on production, the variable outlet back pressure stress sensitivity experiments were applied to test core sample permeability under different burden pressure and obtain the relational expression of power function of core stress sensitivity. Afterwards, new productivity equation is deduced in consideration of reservoir stress sensitivity, and the affection of stress sensitivity on production is analyzed. The result demonstrates close link between stress sensitivity and productivity, since single well production decreases dramatically when reservoir stress sensitivity has been taken into account. This research is constructive for well-testing data interpretation in stress sensitive gas reservoirs.
\end{abstract}

\section{Keywords}

Ying-Qiong Basin, Abnormal High-Pressure, Gas Reservoir, Stress Sensitivity, Productivity Analysis

\section{Introduction}

Stress sensitivity refers to the phenomenon that permeability changes along with the effective stress in the production process of oil or gas pay. Abundant experiments showed that high-pressure gas reservoirs, especially those of low-permeability have stress sensitivity [1] [2] [3] [4]. Middle-deep layers of Ying-Qiong Basin in the west of South China Sea contain abnormal high-pressure (formation pressure coefficient is larger than 1.8) gas reservoirs, most of which present intense stress sensitivity during depletion development. Plenty of researches have 
been done abroad on stress sensitivity and productivity of this type of gas reservoir. However, they confound the concept of effective stress with producing pressure drop when they establish the productivity equation. Based on former studies, this research discussed the influence of stress sensitivity on reservoir physical properties and gas well production through experiments and productivity test analysis, deduced the productivity equation that takes stress sensitivity into consideration, on the basis of revised stress sensitivity equation and gas reservoir seepage feature, and eventually applied this equation for productivity analysis of gas reservoirs in Ying-Qiong Basin.

\section{Stress Sensitivity Analysis}

Utilize HYKS-III high-temperature burden pressure porosity and permeability measuring instrument to conduct variable outlet back pressure stress sensitivity experiments and take core samples from the third phase of Meishan Formation in LS13A gas field. Figure 1 shows the representative core permeability stress sensitivity curve. This core sample stimulates the under changing pore pressure. Like other cores with similar permeability stress sensitivity curve, whose permeability stress sensitivity is weak, permeability of this sample presents exponential change in either the process of pressure increase or decrease. It shall be concluded from the perspective of permeability variation trend that the permeability damage of this core is not severe.

To combine experimental result with theory, core stress sensitivity index is calculated to evaluate the stress sensitivity degree [5]. The index expression is as follow:

$$
\gamma=-\frac{1}{k} \frac{\mathrm{d} k}{\mathrm{~d} P}
$$

Integrate the expression above:

$$
k=k_{i} \mathrm{e}^{-\gamma\left(\sigma-\sigma_{i}\right)}
$$

$\gamma$ is the stress sensitivity index, $\mathrm{M} \cdot \mathrm{Pa}^{-1}$.

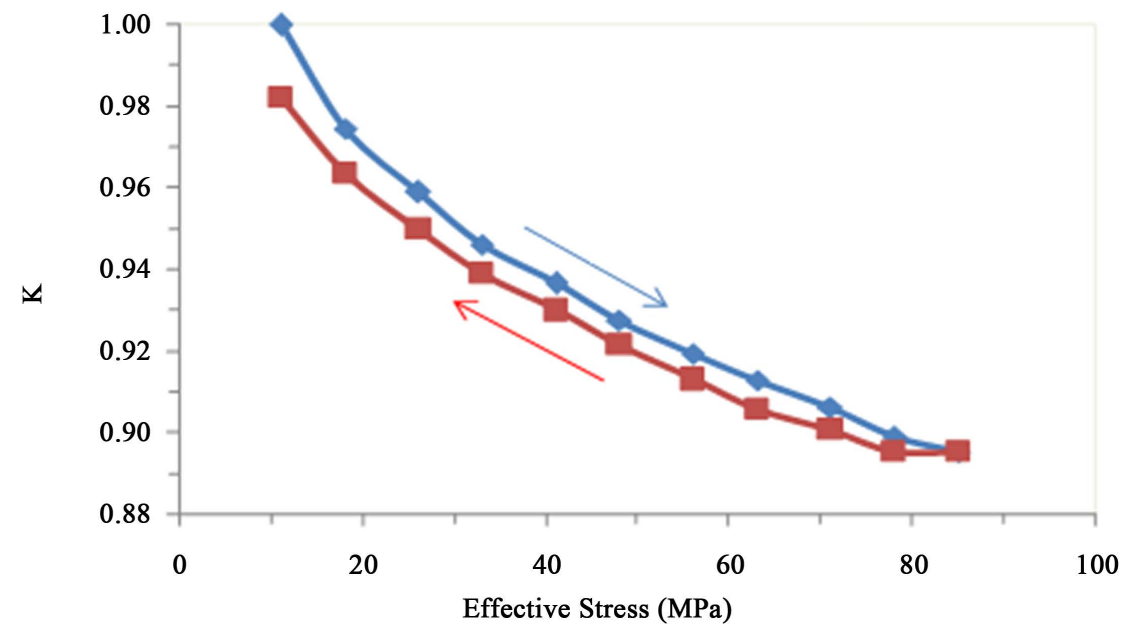

Figure 1. Core permeability stress sensitivity curve (variable pore pressure). 
Take natural logarithm of 1 , the result is:

$$
\ln \frac{k}{k_{i}}=\gamma\left(\sigma-\sigma_{i}\right)
$$

Treat $\left(\sigma-\sigma_{i}\right)$ as independent variable and $\ln \frac{k}{k_{i}}$ as dependent variable. According to experiment data, stress sensitivity index $-\gamma$ of each core shall be calculated by least square method.

Use stress sensitivity experiment data to calculate $\ln \frac{k}{k_{i}}$ on each $\left(\sigma-\sigma_{i}\right)$ point. Then take $\left(\sigma-\sigma_{i}\right)$ as $\mathrm{X}$-axis and $\ln \frac{k}{k_{i}}$ as $\mathrm{Y}$-axis, and the stress sensitivity index is obtained as 0.0247 through data fitting.

\section{Productivity Equation Considering Stress Sensitivity}

\subsection{Productivity Analysis without Consideration of Stress Sensitivity}

The basic assumptions are: a vertical well in an isothermal, infinite, horizontal, isotropy gas reservoir with seal on top and bottom, that has stable thickness- $h$, initial pressure- $p_{i}$, slightly compressible fluid with comprehensive compress index- $C_{t}$ and gas viscosity- $\mu$. Single phase seepage is taken into consideration while gravity and capillary force are omitted.

From Darcy model:

$$
Q \frac{Z T p_{s c}}{T_{s c} p}=v A=\frac{2 \pi r h k}{\mu} \frac{\mathrm{d} p}{\mathrm{~d} r}
$$

In terms of deviated well productivity calculation, skin coefficient is introduced into the equation, which is:

$$
S_{\theta}=(1-\cos \theta) \ln \frac{4 r_{w}}{L}+\frac{1}{2} \cos \theta \ln \cos \theta
$$

Integrate Expression (3.1):

$$
Q=\frac{\pi r h k T_{s c} 2 p}{T p_{s c} \mu Z} \frac{\mathrm{d} p}{\mathrm{~d} r}=\frac{\pi k h T_{s c}}{T p_{s c}} \frac{\mathrm{d} \psi}{r \mathrm{~d} r}=\frac{\pi k h T_{s c}}{T p_{s c}} \frac{\psi_{e}-\psi_{w}}{\left(\ln \frac{r_{e}}{r_{w}}-\frac{3}{4}+S+S_{\theta}\right)}
$$

Expression (3.3) is deviated well productivity equation under Darcy model without consideration of stress sensitivity.

While in high-speed non-Darcy condition:

$$
Q=\frac{\pi k h T_{s c}}{T p_{s c}} \frac{\psi_{e}-\psi_{w}}{\left(\ln \frac{r_{e}}{r_{w}}-\frac{3}{4}+S+S_{\theta}+D Q\right)}
$$

Expression (3.4) is deviated well productivity equation considering high-speed non-Darcy effect without consideration of stress sensitivity. 


\subsection{Deviated Well Productivity Analysis Considering Stress Sensitivity}

Reorganize Expression (3.4) to form the Darcy equation considering stress sensitivity:

$$
Q=v A=\frac{2 \pi r h k_{0} \mathrm{e}^{-\gamma\left(p_{i}-p\right)} T_{s c} p}{\mu Z T p_{s c}} \frac{\mathrm{d} p}{\mathrm{~d} r}
$$

Redefine pseudo-pressure function: $\psi^{\prime}=\int_{p_{0}}^{p} \frac{2 \mathrm{e}^{-\gamma\left(p_{i}-p\right)} p}{\mu Z} \mathrm{~d} p$

Integrate Expression (3.5):

$$
Q=\frac{\pi r h k_{0} T_{s c}}{T p_{s c}} \frac{\left(\psi_{e}^{\prime}-\psi_{w}^{\prime}\right)}{\left(\ln \frac{r_{e}}{r_{w}}-\frac{3}{4}+S+S_{\theta}\right)}
$$

Expression (3.6) is deviated well productivity equation considering stress sensitivity.

Take high-speed non-Darcy affection into consideration:

$$
Q=\frac{\pi k h T_{s c}}{T p_{s c}} \frac{\psi_{e}^{\prime}-\psi_{w}^{\prime}}{\left(\ln \frac{r_{e}}{r_{w}}-\frac{3}{4}+S+S_{\theta}+D Q\right)}
$$

Expression (3.7) is deviated well productivity equation considering high-speed non-Darcy effect and stress sensitivity.

Productivity analysis considering stress sensitivity.

In Figure 2, gas well productivity decreases as the increase of stress sensitivity index. Productivity varies little at first, but as production process goes on, stress sensitivity works, leading to remarkable distinction between actual productivity and theoretical productivity.

\section{Practical Application}

The geological parameters of LS13A gas field are formation pressure-65 MPa, average porosity- $10 \%$, permeability- $0.5 \mathrm{mD}$, effective thickness of gas pay-10 m and measured stress sensitivity index-0.0247. The non-Darcy flow index calculated by Chen Qianyuan formula is $0.039172 \times 10^{-4} \mathrm{MPa}^{-1}$. Figure 3 shows the IPR curves with and without consideration of stress sensitivity. Open-flow capacity irrespective of stress sensitivity is $13.86 \times 10^{4} \mathrm{~m}^{3} / \mathrm{d}$, while that considering stress sensitivity is $8 \times 10^{4} \mathrm{~m}^{3} / \mathrm{d}$. The deviation reaches $42.28 \%$, which affects reservoir evaluation dramatically.

\section{Conclusions}

1) The variable outlet back pressure stress sensitivity experiment method can measure core stress sensitivity index effectively and appraise core stress sensitivity.

2) Stress sensitivity is non-negligible in abnormal high-pressure gas reservoir and has greatly affected the accuracy of single well productivity evaluation. The 


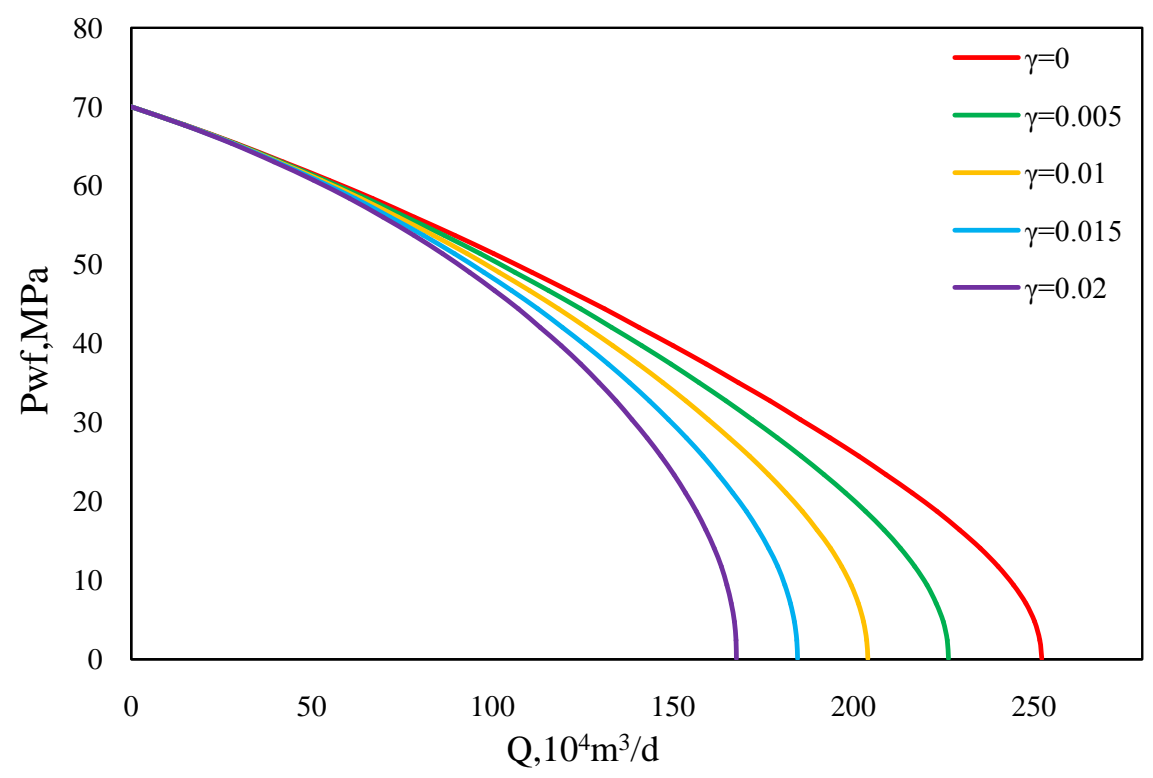

Figure 2. Productivity curve under different stress sensitivity index.

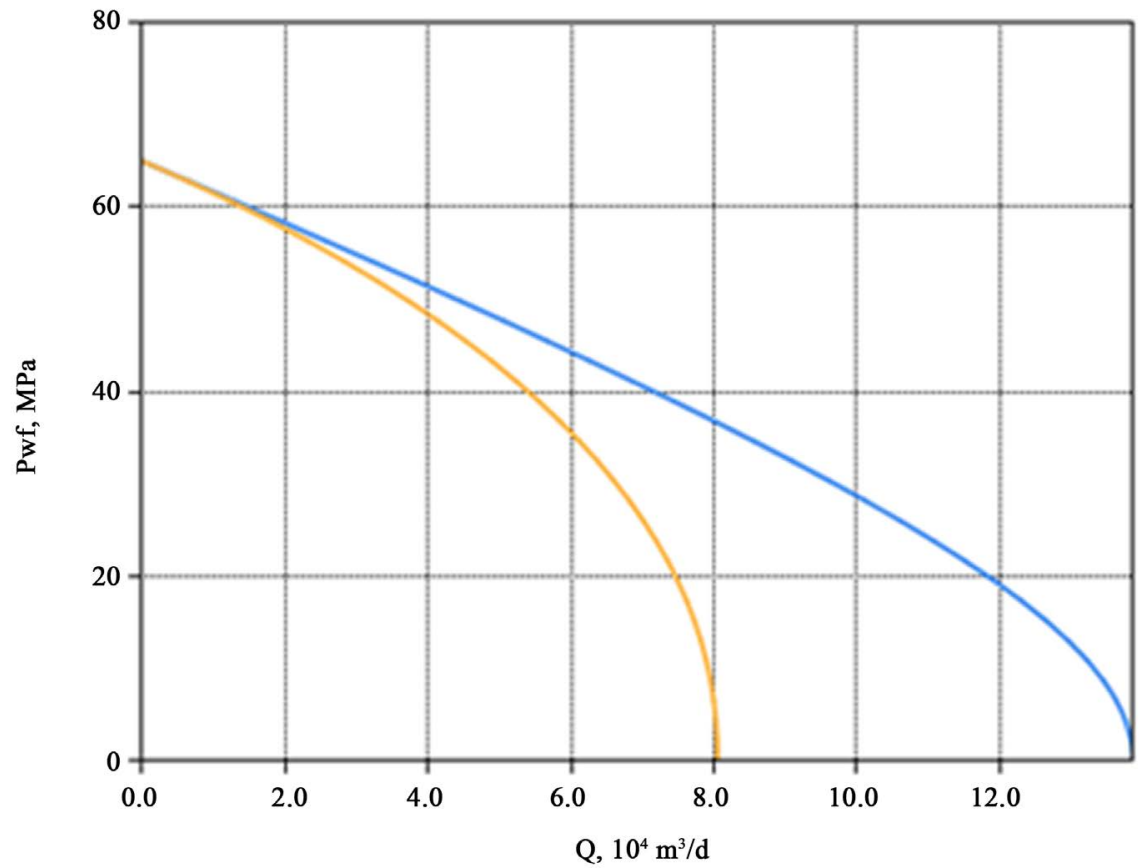

Figure 3. IPR curves with and without consideration of stress sensitivity.

deviation with and without consideration of stress sensitivity is as large as 42.28\% in Well LS13A of Ying-Qiong Basin.

\section{References}

[1] Song, G.S., Xiong, W., Gao, S.S., et al. (2008) A New Method to Study Stress Sensitivity of Tight Reservoir and Its Influence on Oilfield Development. Chinese Journal of Hydrodynamics, 23, 220-225.

[2] Gao, B.Y., Zhou, Y.Y. and Peng, S.M. (2005) Study on the Stress Sensibility of Reservoir Porosity. Petroleum Geology \& Experiment, 27, 197-202. 
[3] Sun, Y.X., Kong, C.L. and Wang, Y.Q. (2009) Stress Sensitivity of Low-Permeability Sandstone Reservoir. Science Technology and Engineering, 9, 4448-4450.

[4] Li, D.Q., Kang, Y.L. and Zhang, H. (2011) New Evaluation Method of Permeability Stress Sensitivity Based on Visual Fracture Aperture Measurement. Natural Gas Geoscience, 22, 494-500.

[5] Lan, L., Kang, Y.L., Chen, Y.J., et al. (2005) Discussion on Evaluation Methods for Stress Sensitivities of Low Permeability and Tight Sandstone Reservoirs. Drilling and Completion Fluids, 22, 1-4.

Submit or recommend next manuscript to SCIRP and we will provide best service for you:

Accepting pre-submission inquiries through Email, Facebook, LinkedIn, Twitter, etc. A wide selection of journals (inclusive of 9 subjects, more than 200 journals)

Providing 24-hour high-quality service

User-friendly online submission system

Fair and swift peer-review system

Efficient typesetting and proofreading procedure

Display of the result of downloads and visits, as well as the number of cited articles Maximum dissemination of your research work

Submit your manuscript at: http://papersubmission.scirp.org/

Or contact nr@scirp.org 